\title{
PERANCANGAN GROUNDING UNTUK LABORATORIUM TEKNIK TEGANGAN TINGGI DI TEKNIK ELEKTRO UNIVERSITAS ISLAM INDONESIA
}

\author{
Wahyudi Budi Pramonoํㅜ, Suyamto ${ }^{2}$, Dimas Satriyo Prabowo ${ }^{1}$ \\ Jurusan Teknik Elektro, Fakultas Teknologi Industri, Universitas Islam Indonesia ${ }^{1,3)}$ \\ Jalan Kaliurang Km. 14,5 Sleman, Yogyakarta 55501 \\ BATAN Yogyakarta ${ }^{2}$ \\ Jalan Babarsari Sleman Yogyakarta \\ E-mail : wahyudi_budi_p@uii.ac.id
}

\begin{abstract}
Grounding is used as a protection equipment so as to prevent damage and protection for laboratory users. In designing the grounding must consider the economic aspect and simplicity. Viewed from the side economics and simplicity grounding rods forms that will be used in the design of grounding are multiple ground rods. Because the design is simple but can be obtained low resistance values. This grounding design used two wells which have different parameters, and the resulting $R I=$ $0.892 \mathrm{Ohm}$ and $R 2=1.5414 \mathrm{Ohm}$. Because the first well has a smaller resistance value, it will be more effective and efficient when the final draft of grounding used two wells which have the same parameters as the first well, which then shunt connected that the smaller the resistance value amounting to $0.446 \mathrm{Ohm}$. In the design of the two wells used eight rod electrodes with a diameter of $16 \mathrm{~mm}$ and a length of each rod 1 meter. The resulting resistance value is very good to use as the installation of grounding in High Voltage Engineering Laboratory. To obtain a low resistance value is influenced by many factors, such as soil resistivity, a long electrode, the electrode fingers and multiplication factor.
\end{abstract}

Keywords : Grounding, Multiple Ground Rods, Resistance.

\section{PENDAHULUAN}

Grounding system adalah sistem
pentanahan yang berfungsi untuk
meniadakan beda potensial antara jumlah
elektron yang berada dalam suatu arus
listrik, sehingga jika ada kebocoran tegangan
atau arus akan langsung dibuang ke bumi.

\subsection{Fungsi Grounding}

- Untuk keselamatan, grounding berfungsi sebagai penghantar arus listrik langsung ke bumi atau tanah saat terjadi kebocoran isolasi atau percikan api pada konsleting. Sehingga dapat melindungi manusia dari electrical shock / sengatan listrik bila terjadi gangguan.

- Dalam instalasi penangkal petir, sistem grounding berfungsi sebagai penghantar arus listrik yang besar langsung ke bumi. Meski sifatnya sama, namun pemasangan kabel grounding untuk instalasi rumah dan grounding untuk penangkal petir pemasangannya harus terpisah.

- Sebagai proteksi peralatan elektronik atau instrumentasi sehingga dapat mencegah kerusakan akibat adanya bocor tegangan.

- Untuk menjaga keselamatan personil dan peralatan-peralatan listrik yang berada di dalam dan sekitar peralatan sumber tegangan tinggi.

Keamanan peralatan tegangan tinggi dan penggunanya menjadi pertimbangan yang utama di dalam Laboratorium Teknik Tegangan Tinggi. Dalam Laboratorium Teknik Tegangan Tinggi sangat diperlukan adanya grounding system yang memiliki nilai tahanan serendah mungkin sesuai dengan ketentuan (Suyamto,2015). Grounding sendiri memiliki banyak fungsi antara lain adalah sebagai perlindungan bagi manusia dari sengatan listrik karena dapat 
mengalirkan arus gangguan langsung ke bumi atau tanah. Selain itu juga sebagai proteksi untuk peralatan elektronik sehingga dapat mencegah terjadinya kerusakan. Untuk mendapatkan kelayakan grounding yang sesuai dengan fungsinya, harus didapatkan nilai tahanan pentanah yang serendah mungkin (wahyono,2012).

Nilai tahanan pentanah yang serendah mungkin dapat diperoleh melalui desain yang baik dan tepat. Perancangan grounding, selain aspek teknis juga harus memperhatikan aspek ekonomi dan kemudahannya. Perancangan grounding yang baik adalah grounding system yang sederhana namun dapat diperoleh nilai tahanan pentanah yang rendah, terlebih biaya yang harus dikeluarkan rendah.

Pengukuran tahanan jenis tanah dilakukan mulai tahap perancangan, sebelum pemasangan dan setelah pemasangan. Bahkan untuk keperluan perawatan pengukuran tahanan jenis tanah harus sering dilakukan dengan memperhatikan kondisi musimnya. Hasil pengukuran tahanan jenis tanah ini akan menggambarkan kualitas tahanan grounding - nya, semakin besar nilai tahanan jenis tanah menunjukan bahwa kualitas tanah semakin buruk serta nilai besar kecilnya resistansi bergantung pada nilai tahanan jenis tanah (Novianti,2009).

Selain tahanan jenis tanah, kedalaman penanaman batang elektroda pentanahan juga akan berpengaruh terhadap tahanan pentanahannya. Kedalaman optimal perlu dicari agar nilai resistansi jenis tanah dan tahanan pentanahannya dapat diperoleh serendah mungkin (Zulfikar,2012).

Penelitian ini akan merancang grounding system untuk Laboratorium Teknik Tegangan Tinggi dengan mempertimbangkan kondisi terburuk dari tahanan jenis tanah dan tinjauan aspek ekonominya. Perencanaan grounding yang akan dibuat ini akan memperhatikan 5 jenis parameter. Parameter tersebut adalah tahanan jenis tanah, panjang batang elektroda, jari - jari batang elektroda, jumlah batang elektroda, dan faktor perkalian untuk multiple rods yang dapat mempengaruhi nilai tahanannya.

\subsection{Syarat Instalasi Grounding yang Efektif}

- Tahanan pentanah harus memenuhi syarat yang diinginkan untuk suatu keperluan pemakaian.

- Elektroda yang ditanam harus dari bahan konduktor yang baik, tahan korosi dan cukup kuat.

- Elektroda harus mempunyai kontak yang baik dengan tanah di sekelilingnya.

- Tahanan pengetanahan harus baik untuk berbagai musim dalam setahun.

- Biaya pemasangan serendah mungkin.

\subsection{Perhitungan Tahanan Pentanah Elektroda Batang}

\subsubsection{Multiple Ground Rods}

Pentanahan multiple rods menggunakan beberapa elektroda batang yang ditanam secara tegak lurus vertikal ke dalam tanah dengan satu tahanan jenis. Penanamannya dapat membentuk satu garis lurus, segitiga, empat persegi panjang, atau lingkaran dengan jarak antara batang - batang elektroda adalah sama atau simetris. Besar tahanan pentanahnya dapat dihitung dengan menggunakan persamaan (Suyamto,2015) :

$R=\frac{\frac{\rho}{2 \pi L}\left[\ln \frac{4 L}{a}-1\right]}{n} \times F$

Dengan :

$\mathrm{R}=$ Tahanan Pentanahan

$\rho=$ Tahanan Jenis Tanah.

$\mathrm{n}=$ Jumlah Elektroda Batang.

$\mathrm{L}=$ Panjang Batang

$\mathrm{F}=$ Faktor Perkaliam Untuk Pentanahan Multiple Rods 
Faktor perkaliam untuk pentanahan multiple rods menurut IEEE Std 142-2007, IEEE Recommended Practice For Grounding Of Industrial and Commercial Power Systems ditunjukan pada tabel 1.

Tabel.1 Faktor Perkalian untuk Pentanahan Multiple Rods

\begin{tabular}{|c|c|}
\hline $\begin{array}{c}\text { Jumlah Elektroda } \\
\text { Batang }\end{array}$ & F \\
\hline 2 & 1,16 \\
3 & 1,29 \\
4 & 1,36 \\
8 & 1,68 \\
12 & 1,80 \\
16 & 1,92 \\
20 & 2,00 \\
& \\
\hline
\end{tabular}

\section{METODE PENELITIAN}

\subsection{Metode Perancangan}

Metode perancangan yang dilakukan meliputi seluruh proses perancangan grounding untuk Laboratorium Teknik Tegangan Tinggi di Teknik Elektro Universitas Islam Indonesia ini. Berikut alur penelitian yang dilakukan seperti pada gambar 1. Diagram Alir (flow chart) Penelitian.

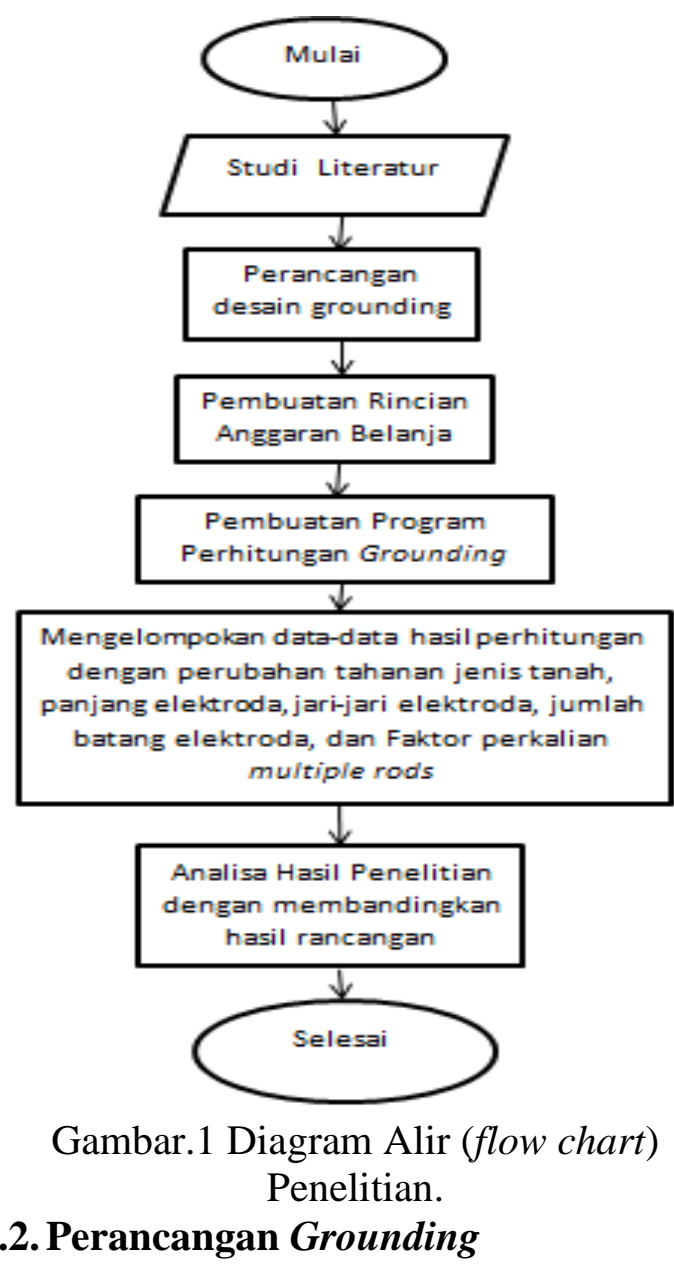

Tahap ini bertujuan untuk mendapatkan desain yang tepat sehingga dapat dihasilkan nilai tahanan pentanah yang rendah. Rancangan desain grounding ini terdiri dari dua buah sumur berdiameter masing-masing 1 meter dengan kedalaman mencapai air tanah. Pada sumur pertama akan ditanamkan 8 buah batang elektroda dengan panjang masing-masing 1 meter yang berdiameter 16 mm. Setiap batang elektroda diikat menggunakan baut suri dan disambung dengan kawat $\mathrm{BC}$ yang terbuat dari lilitan tembaga ukuran $50 \mathrm{~mm}$. Masing-masing batang elektroda yang sudah disambungkan dengan kawat $\mathrm{BC}$ dihubungkan menjadi satu yang kemudian ditarik kawat BC ke atas permukaan tanah. Kemudian dilakukan modifikasi tanah dengan ditimbun tanah liat dan diberi air agar diperoleh nilai tahanan yang kecil. Karena tahanan jenis dari tanah sangat berpengaruh terhadap nilai tahanan tanahnya. 
Sedangkan sumur kedua memiliki spesifikasi yang sama dengan sumur kedua, tetapi jumlah dan panjang elektrodanya yang berbeda, yaitu 4 buah elektroda dengan panjang masing - masing $2 \mathrm{~m}$.

\subsubsection{Perancangan Sumur Pertama Dengan 8 Buah Batang Elektroda}

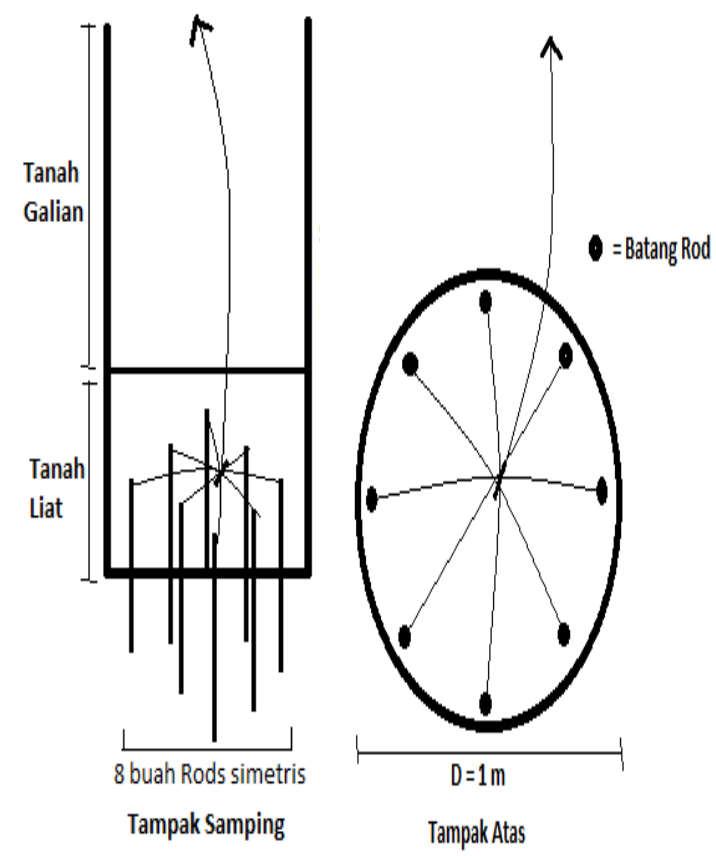

Gambar.2 Rancangan Sumur Pertama.

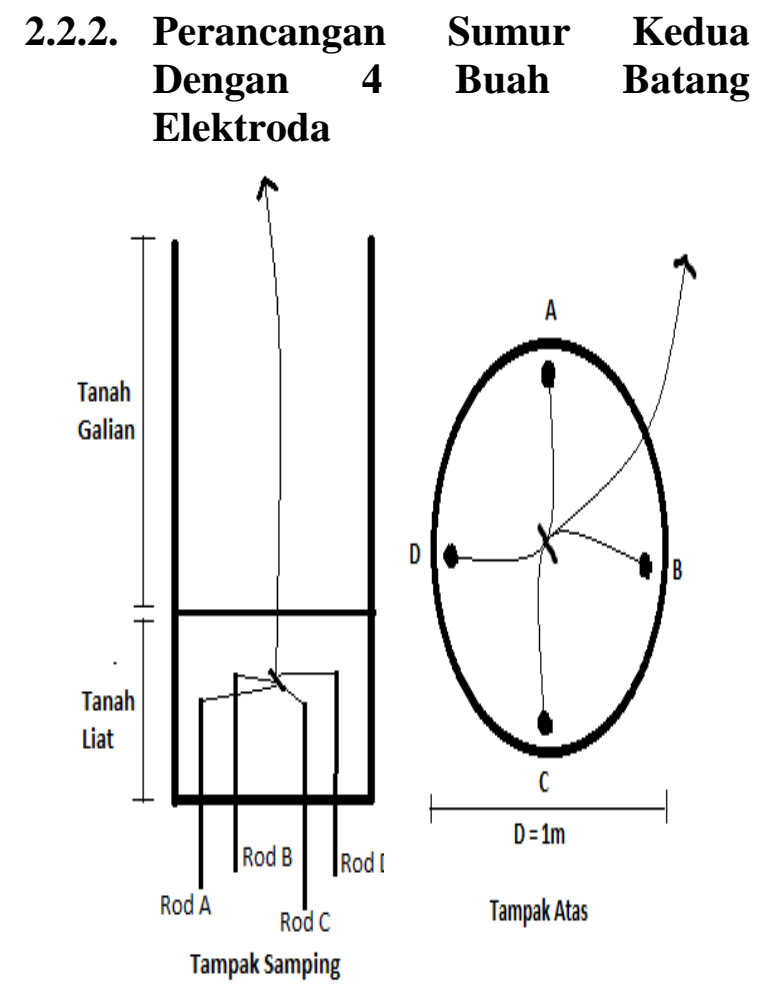

Gambar.3 Rancangan Sumur Kedua.

\subsection{Perhitungan Nilai Resistansi}

Berdasarkan rancangan grounding, maka secara sistematis dapat dihitung dengan persamaan (1) berapa besar nilai tahanan pentanah yang akan dihasilkan.

\subsubsection{Parameter sumur pertama}

Pada sumur pertama diketahui data sebagai berikut :

a. Tahanan Jenis Tanah $=43.80$ Ohm meter.

b. Panjang Batang Elektroda $=1$ meter.

c. Jari - jari Batang Elektroda $=0.8 \mathrm{~cm}$.

d. Jumlah Batang Elektroda $=8$ batang.

e. Faktor Perkalian $=1,68$.

\subsubsection{Parameter Sumur Kedua}

Pada sumur kedua diketahui data sebagai berikut :

a. Tahanan Jenis Tanah $=43.80$ Ohm meter.

b. Panjang Batang Elektroda $=2$ meter.

c. Jari - jari Batang Elektroda $=0.8 \mathrm{~cm}$.

d. Jumlah Batang Elektroda $=4$ batang.

e. Faktor Perkalian $=1,36$.

Material yang digunakan dalam sumur pertama dan sumur kedua sama persis, hanya jumlah dan panjang rod yang berbeda.

\subsection{Perhitungan Resistansi Dengan Perubahan Beberapa Paremeter}

Pada tahap ini akan dihitung nilai tahanan pentanah dengan melakukan perubahan pada beberapa parameter. Parameter yang akan dilakukan perubahan untuk perbandingan perhitungan antara lain adalah tahanan jenis tanah atau $(\rho)$ dengan mengambil tanah liat dan tanah rawa dengan range 30 - 100 Ohm meter, yang kedua adalah panjang batang elektroda (L), kemudian jari - jari dari batang elektroda itu sendiri (a), jumlah batang elektroda yang akan ditanam ke dalam tanah (n), dan faktor perkalian (F) untuk pentanahan multiple rods nilainya 
akan mengikuti dari jumlah batang elektroda yang akan digunakan.

\subsection{Mengelompokan Data - Data Hasil Perhitungan Beberapa Parameter}

Pada tahap ini akan dibuat tabel yang digunakan untuk memudahkan dalam mengelompokan hasil dari perhitungan dengan merubah beberapa parameter. Selain itu juga digunakan untuk memudahkan dalam menganalisa data yang dihasilkan. Sehingga dapat dilihat perubahan yang terjadi pada nilai tahanan pentanah akibat dari mengubah nilai parameter-parameter yang dilakukan tersebut. Nilai dari hasil perhitungan tersebut akan dikelompokan berdasarkan parameter yang telah diubah dalam perhitungan persamaan (1).

\section{HASIL PENELITIAN DAN PEMBAHASAN}

\subsection{Hasil Perhitungan Dengan Beberapa Parameter}

Data - data hasil perhitungan yang telah dihitung dikelompokkan berdasarkan parameter - parameter yang telah diubah untuk memudahkan dalam menganalisanya. Parameter tersebut adalah tahanan jenis tanah, panjang batang elektroda, jari-jari batang elektroda, dan jumlah batang elektroda yang akan diikuti perubahan dari nilai faktor perkalian (F). Dengan nilai - nilai parameter yang tetap atau tidak diubah adalah nilai dari perhitungan rancangan grounding pada sumur pertama sebagai acuan untuk membandingkan. Karena pada sumur pertama dengan persamaan (1), memiliki nilai tahanan pentanah sebesar 0,892 Ohm meter yang lebih kecil dibandingkan nilai tahanan pentanah pada sumur kedua sebesar 1,542 Ohm meter. Nilai tahanan pentanah dari sumur pertama dan sumur kedua dihitung berdasarkan kondisi kandungan air yang paling minimal, yaitu 10 $\%$ dan menggunakan tahanan jenis tanah liat. Sehingga akan diperoleh data - data sebagai berikut :

\subsection{Mengubah Beberapa Nilai Dari Parameter Tahanan Jenis Tanah}

Parameter pertama yang diubah adalah nilai tahanan jenis tanahnya dengan memperhatikan kadar air yang terkandung didalam tanah. Tahanan jenis tanah yang diambil adalah tanah liat dan tanah rawa dengan range tahanan jenis tanahnya seperti pada tabel 1. Hasil perhitungannya adalah sebagai berikut :

Tabel.1 Hasil Perhitungan Tahanan

Tanah Dengan Merubah Tahanan Jenis Tanah

\begin{tabular}{|c|c|c|c|}
\hline NO & $\begin{array}{c}\text { Kadar } \\
\text { Air } \\
(\%)\end{array}$ & $\begin{array}{c}\text { Tahanan Jenis } \\
\text { Tanah } \\
\text { (Ohm meter) }\end{array}$ & $\begin{array}{c}\text { Tahanan } \\
\text { Tanah } \\
(\text { Ohm })\end{array}$ \\
\hline 1 & 10 & 34,18 & 0,69656 \\
2 & 20 & 22,12 & 0,45079 \\
3 & 30 & 18,35 & 0,37396 \\
4 & 40 & 15,53 & 0,31649 \\
5 & 50 & 14,47 & 0,29489 \\
6 & 60 & 14,19 & 0,28918 \\
7 & 70 & 13,27 & 0,27043 \\
8 & 80 & 12,83 & 0,26147 \\
\hline
\end{tabular}

Berdasarkan tabel 1 diatas, dapat dilihat bahwa adanya perbedaan hasil nilai tahanan pentanah yang dihasilkan dari proses perhitungan. Semakin banyak kadar air maka tahanan jenis tanahnya semakin kecil dan tahanan pentanahnya juga akan semakin kecil. Dapat dilihat pada gambar 4, hubungan antara tahanan tanah dan kadar air, penambahan kadar air yang sangat berpengaruh terhadap nilai tahanan tanahnya adalah sebesar 20\%. Kenaikan kadar air tanah diatas $20 \%$ pengaruhnya sedikit terhadap nilai tahanan tanahnya (Suyamto,2015). Pada perancangan ini akan dilakukan modifikasi tanah dengan menggunakan tanah liat dan diberi kadar air agar diperoleh nilai tahanan pentanah yang semakin kecil. 


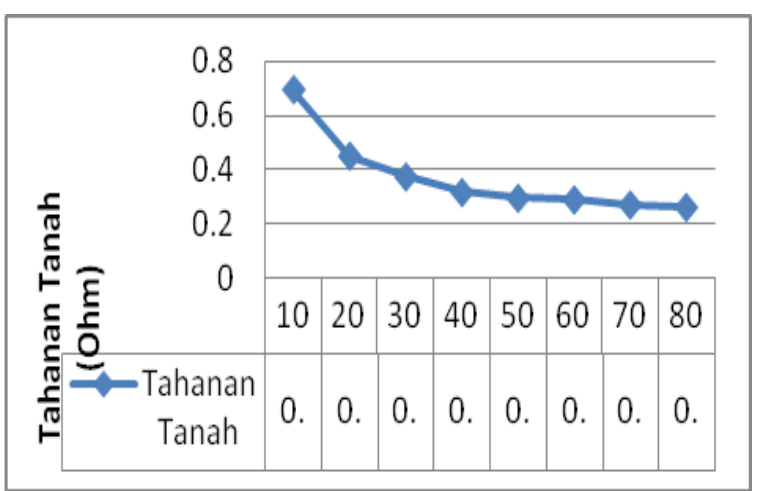

Gambar.4 Hubungan Antara Tahanan

Tanah Dengan Kadar Air Dalam

Tanah.

\subsection{Mengubah Beberapa Nilai Dari Parameter Panjang Elektroda}

Parameter kedua yang diubah adalah nilai dari panjang batang elektrodanya. Panjang batang elektroda dapat dipotong sesuai dengan yang diinginkan. Hasil perhitungannya adalah sebagai berikut :

Tabel.2 Hasil Perhitungan Tahanan Tanah Dengan Merubah Panjang Elektroda

\begin{tabular}{|c|c|c|}
\hline NO & $\begin{array}{c}\text { Panjang } \\
\text { Elektroda } \\
(\mathrm{m})\end{array}$ & $\begin{array}{c}\text { Tahanan } \\
\text { Tanah } \\
(\text { Ohm })\end{array}$ \\
\hline 1. & 1 & 0,8926 \\
2. & 2 & 0,9539 \\
3. & 4 & 0,7307 \\
\hline
\end{tabular}

Berdasarkan tabel 2 diatas, dapat dilihat bahwa adanya perbedaan hasil nilai tahanan pentanah yang dihasilkan dari proses perhitungan. Semakin panjang batang elektroda yang ditanam maka tahanan pentanahnya akan semakin kecil walaupun perubahannya tidak terlalu besar atau signifikan (Suyamto, 2012). Dapat disimpulkan bahwa panjang batang elektroda berpengaruh terhadap besar dari nilai tahanan pentanah walaupun tidak terlalu besar pengaruhnya.

\subsection{Mengubah Beberapa Nilai Dari Parameter Jari - Jari Elektroda}

Parameter ketiga yang diubah adalah nilai dari jari - jari batang elektrodanya. Jari - jari batang elektroda yang berbeda - beda maka akan berpengaruh terhadap besar dari nilai tahanan tanahnya. Hasil perhitungannya adalah sebagai berikut :

Tabel.3 Hasil Perhitungan Tahanan Tanah

Dengan Merubah Jari - Jari Elektroda

\begin{tabular}{|c|c|c|}
\hline NO & $\begin{array}{c}\text { Jari-jari } \\
\text { Batang } \\
\text { Elektroda } \\
(\mathrm{cm})\end{array}$ & $\begin{array}{c}\text { Tahanan } \\
\text { Tanah } \\
(\text { Ohm })\end{array}$ \\
\hline 1 & 0,5 & 1,5810 \\
2 & 0,8 & 0,8926 \\
\hline
\end{tabular}

Berdasarkan tabel 3 diatas, dapat dilihat bahwa semakin besar jari-jari batang elektroda yang digunakan maka tahanan pentanahnya akan semakin kecil. Begitu juga sebaliknya, dengan jari-jari batang elektroda yang semakin kecil maka tahanan pentanahnya akan semakin besar. Dapat disimpulkan bahwa besarnya jari-jari batang elektroda yang digunakan berpengaruh terhadap besarnya nilai tahanan pentanah.

\subsection{Mengubah Beberapa Nilai Dari Parameter Jumlah Batang Elektroda}

Parameter keempat yang diubah adalah jumlah batang elektroda yang akan ditanam ke dalam tanah (n) dengan mengikuti perubahan dari nilai faktor perkalian $(\mathrm{F})$ untuk pentanahan multiple rods yang digunakan. Hasil perhitungannya adalah sebagai berikut :

Tabel.4 Hasil Perhitungan Tahanan Tanah Dengan Mengubah Jumlah Batang Elektroda

\begin{tabular}{|c|c|c|c|}
\hline NO & $\begin{array}{c}\text { Jumlah } \\
\text { Batang } \\
\text { Elektroda }\end{array}$ & $\begin{array}{c}\text { Faktor } \\
\text { Perkalian }\end{array}$ & $\begin{array}{c}\text { Tahanan } \\
\text { Tanah } \\
\text { (Ohm) }\end{array}$ \\
\hline 1 & 2 & 1,16 & 2,4653 \\
2 & 3 & 1,29 & 1,8277 \\
3 & 4 & 1,36 & 1,4451 \\
4 & 8 & 1,68 & 0,8926 \\
\hline
\end{tabular}


Berdasarkan tabel 4, dapat dilihat bahwa adanya perbedaan hasil nilai tahanan pentanah yang dihasilkan dari proses perhitungan. Semakin banyak jumlah batang elektroda yang digunakan maka nilai faktor perkaliannnya juga akan semakin besar tetapi tahanan pentanahnya akan semakin kecil. Oleh karena itu untuk memperoleh tahanan pentanah yang lebih kecil gunakanlah bentuk multiple rods dengan jumlah batang elektroda yang banyak.

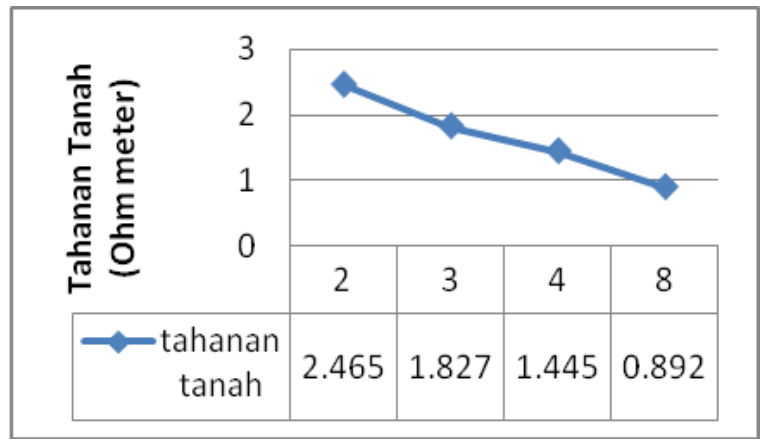

Gambar 5. Hubungan Antara Jumlah

Batang Elektroda Dengan

Tahanan Tanah.

\subsection{Pembahasan Rancangan Grounding}

Pada perancangan desain grounding yang telah dibuat, menggunakan dua buah sumur yang masing - masing sumur memiliki ketentuan yang berbeda. Nilai tahanan pentanah pada sumur pertama yaitu sebesar 0,8920 Ohm. Sedangkan nilai tahanan pentanah pada sumur kedua yaitu sebesar 1,5414 Ohm. Hal tersebut dapat terjadi karena setiap sumur yang dirancang dengan spesifikasi ketentuan yang berbeda. Dengan tahanan jenis tanah dan jari - jari batang elektroda yang sama, tetapi memiliki panjang batang elektroda dan jumlah batang elektroda yang berbeda termasuk pada nilai faktor perkalian untuk pentanahan multiple rods mempengaruhi nilai dari tahanan pentanahnya. Nilai tahanan pentanah pada sumur pertama lebih kecil dari pada nilai tahanan pentanah pada sumur kedua karena pada sumur pertama memiliki jumlah batang elektroda yang lebih banyak dari pada jumlah batang elektroda yang kedua. Jumlah batang elektroda yang digunakan sangat berpengaruh terhadap hasil nilai tahanan pentanah.

Walaupun panjang batang elektrodanya lebih panjang pada sumur kedua, tetapi hasil nilai tahanan pentanahnya lebih kecil sumur yang pertama. Hal tersebut dapat terjadi karena panjang batang elektroda berpengaruh terhadap besarnya nilai tahanan pentanah hanya saja tidak terlalu besar pengaruhnya. Nilai faktor perkalian juga berubah sejalan dengan perubahan yang terjadi pada jumlah batang elektroda yang digunakan. Jumlah batang elektroda yang digunakan lebih banyak maka faktor perkaliannya juga semakin besar. Dan dengan faktor perkalian yang semakin besar maka nilai tahanan pentanahnya akan semakin kecil. Dilihat dari faktor ekonominya sumur pertama dan kedua tidak ada yang berbeda, karena jumlah batang elektroda yang harus dibeli dari pasaran jumlahnya sama.

\subsection{Rancangan Grounding Akhir}

Berdasarkan perhitungan dan analisa rancangan grounding yang sudah dilakukan dapat dibuat rancangan grounding akhir yang akan digunakan sebagai rancangan grounding untuk Laboratorium Teknik Tegangan Tinggi di Teknik Elektro Universitas Islam Indonesia. Berdasarkan perhitungan yang sudah dilakukan rancangan sumur pertama memiliki nilai tahanan pentanah yang lebih besar dibandingkan sumur kedua. Maka akan lebih efektif dan efisien apabila rancangan grounding ini menggunakan dua buah sumur yang diparalelkan tetapi kedua sumur tersebut menggunakan spesifikasi seperti pada rancagan sumur pertama.

Karena rancangan sumur pertama menghasilkan nilai tahanan pentanah yang lebih kecil, sehingga apabila kedua sumur tersebut menggunakan nilai seperti pada rancangan sumur pertama yang diparalelkan akan menghasilkan nilai tahanan pentanah yang semakin kecil dan lebih bagus lagi. Dilihat dari faktor ekonominya juga tidak ada yang berbeda. Maka akan diperoleh nilai tahanan pentanah dari kedua sumur tersebut 
dengan spesifikasi seperti pada rancangan sumur pertama yaitu dengan rancangan grounding akhir yang kedua sumurnya diparalelkan menjadi satu dan menggunakan spesifikasi seperti pada rancangan sumur pertama maka akan menghasilkan nilai tahanan pentanah yang semakin kecil, yaitu sebesar 0,446 Ohm. Nilai tahanan pentanah yang dihasilkan tersebut sudah sangat baik untuk digunakan sebagai instalasi grounding di dalam Laboratorium Teknik Tegangan Tinggi.

\section{KESIMPULAN}

Dari perencanaan dan pembahasan yang telah dilakukan dapat ditarik kesimpulan bahwa :

a. Untuk mendapatkan rancangan grounding dengan nilai tahanan pentanah yang rendah sangat dipengaruhi oleh banyak faktor, antara lain tahanan jenis tanah, panjang batang elektroda, jari - jari batang elektroda dan faktor perkalian.

b. Semakin banyak kadar air yang terkandung di dalam tanah maka nilai tahanan jenis tanahnya semakin kecil dan nilai tahanan pentanahnya akan semakin kecil juga. Semakin panjang batang elektroda yang ditanam maka akan semakin kecil nilai tahanan pentanahnya, begitu juga dengan jarijari batang elektroda yang digunakan. Semakin banyak jumlah batang elektroda yang digunakan maka faktor perkaliannya juga akan semakin besar, tetapi nilai tahanan pentanahnya akan semakin kecil.

c. Dengan menggunakan rancangan grounding yang sama maka rancangan pada sumur pertama dan kedua menghasilkan nilai tahanan pentanah masing-masing sebesar 0,892 Ohm. Setelah diparalelkan kedua sumur tersebut menghasilkan nilai tahanan pentanah total sebesar 0,446 Ohm. Nilai tahanan pentanah yang dihasilkan tersebut sudah sangat baik digunakan sebagai instalasi grounding di dalam
Laboratorium Teknik Tegangan Tinggi karena nilai tahanan pentanah yang dihasilkan sudah dibawah nilai $5 \mathrm{Ohm}$.

\section{DAFTAR PUSTAKA}

C. Novianti, "Pengukuran Tahanan Tanah (Grounding)", Jurusan Teknik Elektro, Program Studi Teknik Telekomunikasi, Politeknik Negeri Semarang, 2009.

L. Zulfikar, "Studi Pengaruh Jenis Tanah dan Kedalaman Pembumian Driven Ros Terhadap Resistansi Jenis Tanah", Jurusan Teknik Elektro, Fakultas Teknik, Universitas Islam Makassar, 2012.

Suyamto, Bahan Kuliah Grounding 2014 2015, Yogyakarta, 2015.

Suyamto, Sutadi, Elin Nuraini, "Instalasi dan Evaluasi Grounding untuk MBE Industri Lateks PTAPB Menggunakan Multiple Rods", Pusat Teknologi Akselerator dan Proses Bahan (PTAPB), Badan Tenaga Nuklir Nasional, Yogyakarta. 2012.

Wahyono, "Pengaruh Kadar Air dan Kedalaman Elektroda Batang Tunggal Terhadap Tahanan Pembumian Pada Tanah Liat", Jurusan Teknik Mesin, Politeknik Negeri Semarang, 2012. 